\title{
Promoting High Standards in the Middle East
}

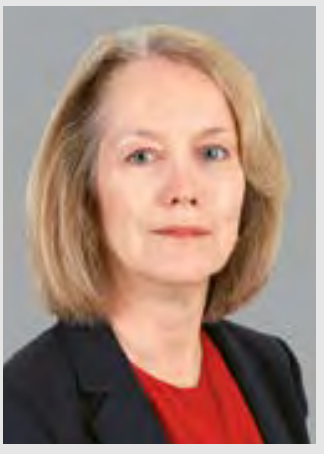

By Christina Rulfs, CFA

Asset managers hold a position of trust with investors across the globe. The Asset Manager Code of Professional Conduct (the Code) is a voluntary code offered by CFA Institute to help asset managers practice ethical principles that put client interests first. As of the beginning of 2016, the Code had not been adopted anywhere in the Gulf region; within three months, however, the region gained four Code-compliant asset managers-in Bahrain, Kuwait, Qatar, and Saudi Arabia. The increased interest and success of the Code in these countries is due to the hard work and collaboration of CFA Institute member societies in the Gulf region over the past few years.

CFA Society Kuwait reviewed a translation of the Code into Arabic provided by CFA Institute in mid-2013. At the Middle East Advocacy Workshop held in Kuwait in February 2015, the other regional societies offered to help develop the translation into a format that could be used by all of the Arabic-speaking countries. CFA Society Egypt in particular took the lead in ensuring that the final translation would be both technically accurate and easily understood throughout the region.

By March 2016, the Arabic translation of the Code had been posted on the website of CFA Institute. At the Advocacy Workshop held in Bahrain a month later, 100 printed copies were distributed among the eight Arabic-speaking societies in attendance. At the same time, two asset managers, one in Qatar and one in Saudi Arabia, either had adopted or were in the process of adopting the Code; shortly after, two additional asset managers, in Bahrain and Kuwait, announced their Code compliance.

CFA Society Kuwait arranged meetings with a number of asset managers following the advocacy workshop in Bahrain. Their objective was to convince one of these firms to be the leader in adopting the Code in their country. One firm in particular, KAMCO, expressed an interest in moving forward quickly, starting the Code-compliance process within a week of the meeting. As is common in adopting the Code, some questions arose as to whether the firm's existing internal processes were already Code compliant. CFA Society Kuwait and CFA Institute were able to quickly respond that the firm's current practices were compliant, and this allowed KAMCO to submit their compliance form within a month of starting the process.

KAMCO was interested in announcing their adoption of the Code, and their press release generated coverage in 10 Arabicand English-language publications. The articles stressed the importance of a commitment to ethics and putting investors first-both core principles of the Code. Local press coverage also highlighted the global reach of the Code and the fact that KAMCO was joining more than a thousand asset managers worldwide already in compliance with the Code.

Although the Arabic translation of the Code and the momentum generated by the first firms to claim compliance undoubtedly played a role in this early success in the region, the credit must go to CFA Institute members and local society leaders. Their advocacy of the codes and standards of CFA Institute, whether individually within their places of employment or as part of a team of society members visiting asset managers, has raised the visibility of both the Code and the CFA charter. The recognition of CFA Institute codes and standards can only grow as a result of this increased cooperation among the membership.

Much can still be done to raise awareness of the Code. One way to build on this early success is to talk with regulators and asset owners about the Code and about other CFA Institute codes and standards. Some member societies are asking asset owners to include a question about Code compliance on requests for proposals (RFPs) distributed to asset managers. Although not publically recognized like asset manager compliance (e.g., at www.cfainstitute.org or through a press release), the importance of having asset owners ask about the Code in their RFPs is not to be underestimated.

In addition to asset managers and asset owners, society leaders have used the Arabic-language version of the Code as an opportunity to contact regulators. Bringing the translated version to policymakers can serve two purposes. First, it highlights the commitment by CFA Institute to codes and standards and opens the door to a broader dialogue on the common goal of strengthening ethics in financial markets. Second, it underlines the importance CFA Institute places on the Gulf region. Heightened awareness of CFA Institute and local member societies among regulators brings opportunities to discuss regulatory scholarships and CFA Program waivers, which in turn build brand recognition.

Productive collaboration between Middle Eastern CFA Institute member societies will not be limited to translating and promoting the Code in the region. Building on society leader discussions at the 2016 Middle East Investment Conference, several local societies recently met in Dubai to discuss combining their efforts in a more formal, coordinated fashion. Joint efforts in the region will cover governance, branding, advocacy, outreach, and better use of resources. Judging by the progress on advocacy so far, member societies are poised to capitalize on their cooperative efforts for even greater impact in the region.

Christina Rulfs, CFA, is director of society advocacy engagement for the EMEA region at CFA Institute. 